\title{
Did Surface Erosion Events Affect Neoproterozoic-Phanerozoic Plate Tectonics?
}

\author{
STEPHAN V. SOBOLEV ${ }^{1,2}$ AND TROND H. TORSVIK ${ }^{3}$
}

${ }^{1}$ GFZ German Research Centre for Geosciences

${ }^{2}$ University of Potsdam

${ }^{3}$ Centre for Earth Evolution and Dynamics

Presenting Author: stephan@gfz-potsdam.de

Despite the obvious importance of plate tectonics for Earth's evolution, its controlling factors remain poorly understood. Recently it was suggested that major surface erosion events provided sediments that lubricated subduction zones and thus controlled the evolution of plate tectonics (Sobolev and Brown, 2019). Before the emergence of continents about $3 \mathrm{Ga}$, the flux of sediments (lubricant) to the trenches was very limited. We suggest that subduction zones were already present at that time but were likely initiated only above the hot mantle plumes, as modeled by Gerya et al. (2015). After the emergence of continents, a regime of intermittent plate tectonics developed in which periods of active plate tectonics followed events of large active continental erosion and an intensive supply of sediments into the ocean. In this study, we test this hypothesis using a model of Phanerozoic plate motions (Torsvik and Cocks, 2017) and other published models from $1 \mathrm{Ga}$ to present, as well as geochemical proxies of the influence of continental sediments in seawater and in magma sources. The modeled plate velocities are relatively slow during the Neoproterozoic and then peak at about 500Ma, 100-200My after the 'snowball Earth' glaciations. The maximum velocity and velocity-decaying trend through most of the Phanerozoic correlates remarkably with the geochemical proxies of the influence of sediments on the composition of seawater and continental crust melt sources. This data and data on the evolution of the length of orogenic belts ( $\mathrm{Li}$ at al., 2019) can be interpreted as the effect of a major surface erosion event during and following snowball Earth glaciations that activated plate tectonics after the so-called 'boring billion', a period of diminished plate tectonic activity (Cawood and Hawkesworth, 2014). The snowball Earth event triggered a number of succeeded collision events that provided sediments to the trenches that lubricated subduction channels. The volume of sediments in trenches decayed with time, likely due to the decreasing length of the continental margins during assemblage of Gondwana-Pangea supercontinent. The decreasing volume of the sediments in trenches caused a reduction of plate velocities. This is a contribution of the ERC Synergy project Monitoring Earth Evolution Through Time (MEET). 